\title{
O cânone da impermanência
}

Thiago Lima Nicodemo ${ }^{1}$

MONTEIRO, Pedro Meira; EUGÊNIO, João Kennedy (Orgs.).

Sérgio Buarque de Holanda: perspectivas. Campinas: Editora da Unicamp, Rio de Janeiro: Editora da UERJ, 2008.

Em diversas entrevistas ao longo de sua vida, ao ser questionado sobre a relevância e atualidade de sua mais conhecida obra, Raízes do Brasil, Sérgio Buarque de Holanda demonstrou certa irritação que chegava até a desconcertar seus interlocutores. Suas palavras enfáticas são bastante elucidativas a esse respeito - "O livro está superado e é plenamente datado" - disse em 1976, em entrevista publicada nas "páginas amarelas" da revista Veja, ou ainda - "É um livro com o qual eu não concordo muito, mas que tem tido grande visibilidade" - como chegou a dizer em seu último depoimento conhecido, gravado em junho de 1981 (publicado em 2004 pela revista Novos Estudos, do Cebrap, no 69).

Um dos principais fatores que levavam o intelectual a reagir desse modo se devia às interpretações equivocadas da ideia de "homem cordial", desde as primeiras reverberações de Raízes do Brasil. Em vez de um instrumento crítico dedicado a diagnosticar traços da esfera familiar e privada que bloqueavam o desenvolvimento de uma ordem pública, impessoal e democrática no Brasil, o "homem cordial" foi interpretado como uma espécie de bondade intrínseca presente no caráter nacional brasileiro, equívoco que o autor fazia questão de ressaltar em qualquer comentário autobiográfico.

Especialmente em suas últimas entrevistas, falando como historiador consagrado, o caráter generalista de seu livro de estreia não parecia lhe agradar. A busca por traços característicos de nossa identidade nacional, o apreço por explicações globais de nossa realidade eram, em sua ótica, fenômenos datados, típicos do ensaísmo social das primeiras décadas do século XX. Como o próprio autor elucidou na mesma entrevista de 1976 concedida à revist $a$ Veja: "Hoje eu não me aventuraria mais a tentar uma empreitada dessa espécie. Simplesmente porque os tempos são outros". Os tempos de então eram, para Sérgio, de forte empenho no

1 Doutorando em História Social na Faculdade de Filosofia, Letras e Ciências Humanas da Universidade de São Paulo. E-mail: thiagonicodemo@usp.br. 
escrutínio acadêmico, "na pesquisa rigorosa e exaustiva. Se não, o resultado são apenas elucubrações, às vezes brilhantes, mas desvinculadas da realidade". Desde que publicou seu livro de estreia e iniciou sua primeira experiência docente na efêmera Universidade do Distrito Federal, o intelectual foi um grande animador do desenvolvimento dos estudos acadêmicos especializados no Brasil e sua importância neste quadro continuou crescente na medida em que o tempo foi passando.

Todavia, Sérgio Buarque tinha consciência de que sua obra passava por um processo de canonização. É o que se vê na entrevista já citada de 1981 (p. 6), quando observa que o prefácio de Antonio Candido inserido na quarta edição de 1967 "deu sorte”; pois popularizou significativamente a obra desde então (hoje, na 27a edição, levando em consideração a edição comemorativa de 2006, publicada pela Companhia das Letras).

Nesse texto, quase tão celebre quanto o próprio livro prefaciado, Candido estabelece uma espécie de cânone das três obras fundamentais para a compreensão do Brasil - além de Raízes do Brasil, Casa grande e senzala, de Gilberto Freyre e Formação do Brasil contemporâneo, de Caio Prado Jr. Falando em primeira pessoa, Candido imprime ao texto um tom de balanço de sua geração, cuja visão da cultura brasileira fora moldada pela leitura dessas obras. Sua perspectiva pressupõe um distanciamento que relativiza sua própria concepção da cultura brasileira, circunscrevendo as obras fundamentais de sua formação como fruto de um momento de inflexão na história do Brasil. Deste modo, o crítico eleva o estatuto das obras a documentos históricos, ou seja, estas obras não podem ser consideradas como simples suporte de informações, mas sim como objetos em si do estudo da cultura, tendo em vista a relação particular com o momento em que foram produzidas e as novas realidades que suas leituras ajudaram a criar nas gerações seguintes.

Além disso, Candido, profundamente familiarizado com as discussões sobre o estatuto de "clássico" e do papel do "cânone" em literatura, utiliza o termo "clássico de nascença” para definir Raizes. O estatuto de clássico reveste a obra de atributos que produzem um efeito de constante renovação, em outras palavras, provocam a sensação de que a obra parece sempre "atual".

A elevação a clássico coincidia também com uma situação política que não pode ser ignorada, afinal de contas, nada mais "atual" do que uma reflexão sobre os entraves históricos de uma democracia de fato no Brasil em plena ditadura militar. Esse fato contribuiu bastante para a reabilitação de Sérgio Buarque de Holanda no pensamento universitário de esquerda no país, em especial em relação ao marxismo uspiano. 
Assim, Antonio Candido habilita a obra de Sérgio Buarque de Holanda como tema legítimo de estudo e reflexão, processo que só se consolidaria após a sua morte, em 1982. Candido, aliás, mostrou-se mais uma vez pioneiro nas interpretações sobre Sérgio Buarque. Poucos meses depois de seu falecimento, o crítico publica o artigo "Sérgio em Berlim e depois" no qual segue aprofundando a compreensão de Raízes do Brasil, sugerindo uma forte relação entre a estruturação desta obra e a viagem de Sérgio Buarque à Alemanha entre os anos de 1929 e 1930.

Algumas linhas gerais interpretativas da obra do historiador seriam estabelecidas de modo consistente poucos anos depois, em 1985, por Maria Odila L. S. Dias. Responsável pelo volume sobre Sérgio Buarque de Holanda da Coleção Grandes Cientistas Sociais dirigida por Florestan Fernandes e publicada pela editora Ática, a autora elaborou uma introdução de cerca de sessenta páginas propondo uma interpretação abrangente da obra do autor, estruturada em fases que coincidiam com a publicação de seus principais livros. O texto enfoca, fundamentalmente, o desenvolvimento da concepção de história de Sérgio Buarque de Holanda, apresentando sua obra como fruto de um encontro crescente, ao longo do tempo, com a historiografia especializada e acadêmica, tema que, como vimos pelas suas entrevistas, era consonante com a interpretação do próprio autor sobre seu percurso. A autora aproxima o seu método interpretativo da hermenêutica e do historicismo alemão, especialmente no que diz respeito ao desenvolvimento de uma narrativa fluida, capaz de se aproximar das pulsações individuais dos sujeitos históricos e, ao mesmo tempo, enquadrá-los em unidades de sentido mais amplo, produzindo assim um forte efeito compreensivo capaz de acessar diversas temporalidades. Além da densidade teórica que permitiu situar a obra de Sérgio Buarque na vanguarda dos debates historiográficos de sua época, o texto de Maria Odila Dias extrapolou a interpretação da obra do historiador para além de Raízes do Brasil, apontando linhas de força temáticas e teóricas presentes ao longo de todo o seu percurso intelectual.

Ainda nos anos 1980, a obra de Sérgio Buarque seria tema de dois volumes comemorativos, o primeiro encabeçado por Francisco de Assis Barbosa e publicado em 1987 na Revista do Brasil (ano 3, no 6) e o segundo, publicado no ano seguinte pelo Instituto de Estudos Brasileiros da USP e o Arquivo Público do Estado de São Paulo, sob o título de Sérgio Buarque de Holanda: vida e obra. Ambos os volumes contam, em sua base, com estudos e depoimentos de amigos e ex-discípulos, sendo que no primeiro aparecem diversos artigos e escritos de circunstância inéditos do historiador. Seguindo essa vertente, o mesmo Francisco de Assis Barbosa, complementando os esforços de Antonio Candido e Maria Odila L. S. 
Dias, publicaria, em 1989, a obra Raizes de Sérgio Buarque de Holanda, uma coletânea de artigos do historiador que destacava a importância de sua obra nos anos anteriores à publicação de Raízes do Brasil. Barbosa ressalta especialmente sua conexão com o ideário modernista e com o próprio movimento ligado à organização da Semana de Arte Moderna de 1922, além de suas atividades como jornalista na Alemanha.

Nos anos 1990 e início da década seguinte, a obra de Sérgio Buarque de Holanda passou a ser tema de estudos acadêmicos monográficos dentre os quais A queda do aventureiro (de Pedro Meira Monteiro, publicado em 1999 pela Editora da Unicamp), dedicado à compreensão da apropriação das categorias weberianas em Raizes do Brasil, e o estudo A conquista do oeste (de Robert Wegner, publicado em 2000 pela Editora UFMG), empenhado na interpretação do bloco de trabalhos do historiador relacionados ao tema da expansão para oeste, tema que seguia o esteio do artigo de Ilana Blaj e Marina Maluf, "Caminhos e fronteiras: o movimento na obra de Sérgio Buarque de Holanda”, publicado em 1990 na Revista de História da USP. Vale lembrar que esse novo panorama foi beneficiado pela criação e abertura ao público, ainda na década de 1980, do Acervo Sérgio Buarque de Holanda na Unicamp que conta tanto com os documentos pessoais (no acervo do Arquivo Central - Siarq/ Unicamp) quanto com a biblioteca do historiador (Biblioteca Central da Unicamp).

Os anos 1990 foram ainda generosos com a obra de Sérgio Buarque de Holanda graças à publicação, em 1991, do inédito inacabado Capítulos de literatura colonial (pela editora Brasiliense), também com a curadoria do amigo, Antonio Candido, e pela organização dos textos de crítica literária publicados ao longo de sua vida em edição organizada por Antônio Arnoni Prado, intitulada O espírito e a letra (pela Companhia das Letras, em 1996, em dois volumes). O estudo sistemático desse corpus ainda está por ser feito mas, seja pela importância da sua reflexão teórica sobre tendências de vanguarda da época, como o new criticism e a estilística, seja pela precisão na avaliação de correntes da literatura brasileira, como a "geração de 45", deve-se rever o papel do autor na história da crítica literária no Brasil. Ademais, a militância de Sérgio Buarque de Holanda na crítica literária pode contribuir para elucidar aspectos fundamentais de seus livros mais conhecidos, tanto no que diz respeito a questões de estilo, quanto no que tange ao desenvolvimento de um método particular de compreensão do passado.

As comemorações relativas ao centenário do historiador, em 2002, parecem ter ratificado sua imagem como o grande precursor brasileiro de uma historiografia cultural. Em um quadro acadêmico de forte 
trânsito de princípios relativistas e pós-modernos, é compreensível que, tendo em vista o legado intelectual de Sérgio Buarque de Holanda, avesso a verdades atemporais, atento aos meandros e sutilezas da linguagem, ciente do caráter parcial e finito do conhecimento, ele fosse confirmado como grande intelectual brasileiro do século XX (como sugerido por Alcir Pécora na página 27 da obra resenhada). A isso se somava o fato de que a história praticada pelo intelectual sempre fora permeada por densidade e rigor no manejo e na crítica dos conceitos e por um sensível domínio do acervo de problemáticas literárias e de crítica.

São justamente os aspectos crítico-literários (levando em consideração ainda sua militância e bagagem modernista), metodológico-historiográficos e filosófico-políticos (bem como programáticos, especialmente em Raízes do Brasil) de seu pensamento que chamam grande parte da atenção dos estudiosos. Nesse contexto, o intelectual foi tema principal de uma edição do caderno Mais!, do jornal Folha de S.Paulo, que contou com colaborações originais de intelectuais renomados das áreas de história, sociologia, filosofia e teoria literária como Peter Burke, Gabriel Cohn, Luis Costa Lima e Maria Sylvia de Carvalho Franco. Apesar do claro tom comemorativo, os artigos são, na maioria, densos e incidem sobre temas polêmicos ou pouco estudados. Além disso, deve-se ainda realçar, em relação ao centenário do autor, o conjunto de comemorações organizadas pela Unicamp, das quais merece destaque um seminário internacional - O histórico na literatura e o literário na história na obra de Sérgio Buarque de Holanda - que frutificaria, nos anos consecutivos, em diversas publicações sobre a obra do autor (como, por exemplo, a obra organizada por Sandra Jatahy Pesavento, Um historiador nas fronteiras: o Brasil de Sérgio Buarque de Holanda), abrindo um conjunto de novas possibilidades interpretativas e propiciando o intercâmbio com intelectuais europeus.

Concebida no início dos anos 2000 para figurar como parte comemorativa do centenário de Sérgio Buarque de Holanda, porém, por motivos editoriais, publicada apenas recentemente, a obra Sérgio Buarque de Holanda: perspectivas, organizada por Pedro Meira Monteiro e João Kennedy Eugênio, apresenta-se como um panorama da fortuna crítica recente do historiador, caracterizando-se justamente por entrecruzar textos, normalmente de circunstância, escritos tanto pelos intelectuais já consagrados, como contribuições de novos autores de pesquisas monográficas, recentes ou em curso, sobre a obra do intelectual.

É significativo que, na introdução da coletânea, os organizadores mencionem a discussão sobre o estatuto do clássico. Segundo os autores, 
a obra pauta-se não pela busca de uma essência, mas por um sentimento oposto, "o de que o clássico é, malgrado seu, uma construção" (p. 15).

Pode-se afirmar que a impertinência e o relativismo intrínsecos à obra de Sérgio Buarque de Holanda estão presentes, em alguma medida, em todos os artigos da coleção, apesar de terem sido concebidos sob diferentes perspectivas teóricas e circunstâncias. O artigo de abertura propõe a questão mencionada na introdução de modo claro. Indagandose sobre as razões pelas quais Sérgio Buarque de Holanda se tornou cânone de nossa intelectualidade, Alcir Pécora apresenta duas hipóteses. A primeira, de caráter negativo, fundamenta-se na dinâmica intelectual pela qual o autor funciona como legitimador do discurso acadêmico pelo simples envelhecimento e institucionalização de suas ideias. A segunda, de caráter positivo, leva em consideração que, no panorama contemporâneo de crise de paradigmas e de certo relativismo, um autor como Sérgio Buarque de Holanda, sensível ao caráter ideológico e parcial do conhecimento, enseja comemorações legítimas (p. 27).

A coletânea divide-se em quatro partes, em que os artigos são aglomerados por temas. A primeira, intitulada Escrita e circunstância, congrega temas que entrecruzam a trajetória do intelectual do autor e as dimensões políticas de seu pensamento. Quem dá o tom é Antonio Candido, por meio do artigo "A visão política de Sérgio Buarque de Holanda", e Richard Graham. Ambos procuram demonstrar o compromisso ativo e militante do historiador com os dilemas do seu presente. Merece destaque ainda Henrique Estrada Rodrigues, que traz contribuição original, baseada em sua recém-defendida tese de doutorado, para a compreensão das implicações filosófico-políticas da reflexão de Sérgio Buarque de Holanda sobre o processo de expansão e ocupação do oeste do Brasil. Na mesma linha do trabalho de Alcir Pécora, Walnice N. Galvão aponta para uma questão que merece aprofundamento, qual seja, o corpus de crítica e historiografia literária do autor. De modo programático, a autora sugere uma edição crítica de textos buarqueanos publicados em diferentes circunstâncias (organizados pelo próprio autor ou póstumos), como "Tentativas de mitologia", "O espírito e a letra", "Cobra de vidro" e "Capítulos de literatura colonial”, os quais, vistos em conjunto, permitiriam uma visão mais abrangente e fidedigna do percurso do autor.

A segunda parte, Raizes do Brasil, reúne textos que tratam daquela que é a obra mais conhecida de Sérgio Buarque de Holanda. Seguindo o mesmo movimento da parte anterior, estão presentes artigos já consagrados a exemplo de Raízes do Brasil: "Uma releitura de Brasil", de Pinheiro Machado, publicado pela primeira vez em 1976, conhecido por ter sido o primeiro a sistematizar o aporte dos conceitos weberianos 
em Raizes do Brasil. Esta seção conta ainda com reflexões pouco conhecidas ou inéditas, como é o caso dos artigos de Roberto Vecchi, Pedro Meira Monteiro e João Cezar de Castro Rocha. A maioria dos autores, nessa parte da coletânea, demonstra rigor e sensibilidade ao observar o trânsito entre fenômenos literários e históricos no delineamento de uma dinâmica crítica. Contam, para isso, tanto com um enfrentamento da questão da modernidade e das figurações do moderno (nos artigos de Conrado Pires de Castro, "Motivos ibéricos e pretextos literários”, e de Berenice Cavalcante, "História e modernismo"), quanto com as estratégias metafóricas e o ímpeto dialético negativo da obra de Sérgio Buarque de Holanda, vistos respectivamente nas contribuições de Edgar de Decca e Maria Odila L. S. Dias.

A terceira parte, cujo título é Erudição e imaginação, inicia-se com contribuições de cunho teórico-metodológico com enfoque nos temas do historicismo e da hermenêutica, discutidos respectivamente por Ernani Chaves e Arno Wehling. Merecem destaque ainda o texto de Ettore Finazzi-Agrò, que procura refletir sobre certo espaço de indistinção entre experiência e fantasia na obra de Sérgio Buarque, e o artigo de João Kennedy Eugênio, que traz substanciais contribuições para a compreensão de Sérgio Buarque de Holanda pré-Raizes do Brasil, introduzindo material inédito e problematizando a concepção organicista do jovem, o que colabora para o conhecimento de algumas matizes ideológicas pouco discutidas mas ainda presentes na sua obra, como o monarquismo.

Por fim, a quarta e última parte trata de Visão do paraíso, obra pouco estudada em comparação a Raízes do Brasil, mas que é fundamental, seja pela sua arquitetura sofisticada, seja pelo papel agregador que desempenha frente aos diversos eixos temáticos dentro da obra do autor, entre as décadas de 1920 e 1950. Luiz Costa Lima demonstra como a faceta de crítico literário de Sérgio Buarque de Holanda, especialmente o uso do filólogo alemão Ernst R. Curtius, orientou a pesquisa topológica dos motivos paradisíacos em Visão do paraíso. Também se destacam os textos de Maria Sylvia de Carvalho Franco e de Ronaldo Vainfas, publicados pela primeira vez em 2002. O primeiro é dedicado ao descortinamento das imagens românticas que subjazem à obra referida, e o segundo problematiza a obra de Sérgio Buarque de Holanda dentro das correntes historiográficas internacionais da segunda metade do século XX, com ênfase na assim chamada história das mentalidades.

O livro ainda contém, no seu final, uma reunião de alguns textos pouco conhecidos de Sérgio Buarque de Holanda, dentre os quais merecem relevo dois inéditos pré-Semana de 22, o ensaio "Corpo e alma do Brasil”, publicado pela revista Espelho, em 1935, e que ajuda a esclare- 
cer muito Raízes do Brasil, e o quase inédito "O pensamento histórico no Brasil nos últimos 50 anos", publicado uma única vez no Correio $d a$ Manhã, em 1951. Traz ainda, por fim, o imperdível "Elementos básicos da nacionalidade", texto de conferência proferida em 1967, em que, ao traçar um perfil crítico da história do Brasil, Sérgio Buarque de Holanda desmonta o aparato ideológico do governo militar em plena Escola Superior de Guerra. 